\title{
Mechanisms of Gas Exchange Abnormality in Patients with Chronic Obliterative Pulmonary Vascular Disease
}

\author{
David R. Dantzker and James S. Bower, Pulmonary Division, \\ Department of Internal Medicine, University of Michigan Medical Center, \\ Ann Arbor, Michigan 48109
}

\begin{abstract}
A B S T R A C T We have examined the mechanisms of abnormal gas exchange in seven patients with chronic obliteration of the pulmonary vascular bed secondary to recurrent pulmonary emboli or idiopathic pulmonary hypertension. All of the patients had a widened alveolararterial oxygen gradient and four were significantly hypoxemic with arterial partial pressures of oxygen $<80$ torr. Using the technique of multiple inert gas elimination, we found that ventilation-perfusion $\left(\dot{V}_{A} / \dot{Q}\right)$ relationships were only minimally abnormal with a mean of $10 \%$ (range, $2-19 \%$ ) of cardiac output perfusing abnormal units. These units consisted of shunt and units with $\dot{\mathrm{V}}_{\mathrm{A}} / \dot{\mathrm{Q}}$ ratios $<0.1$. In addition, the dead space was found to be normal in each patient. There was no evidence for diffusion impairment, and the widened alveolar-arterial oxygen gradient was completely explained by $\dot{\mathrm{V}}_{\mathrm{A}} / \dot{\mathrm{Q}}$ inequality. Significant hypoxemia occurred only when $\dot{\mathrm{V}}_{\mathrm{A}} / \dot{\mathrm{Q}}$ inequality was combined with a low mixed venous oxygen content.
\end{abstract}

\section{INTRODUCTION}

Chronic obliterative pulmonary vascular disease without associated parenchymal lung disease occurs in patients with recurrent pulmonary emboli $(\mathrm{RPE})^{1}$ and idiopathic pulmonary hypertension (IPH). Obliteration of the pulmonary vascular bed in these patients results in an elevation of pulmonary artery pressure and a widened alveolar-arterial oxygen gradient $\left(\mathrm{A}-\mathrm{a} \mathrm{DO}_{2}\right)(\mathrm{l})$. Although the widening of the $\mathrm{A}-\mathrm{aDO}{ }_{2}$ may be substantial, the mechanisms of abnormal gas exchange have not been established.

The prognosis of patients with obliterative pulmonary vascular disease is poor (2), but recent attempts at phar-

Received for publication 10 April 197.9 and in revised form 8 June 1979.

${ }^{1}$ Abbreviations used in this paper: $\left.\mathrm{A}-\mathrm{aDO}\right)_{2}$, alveolararterial oxygen gradient; IPH, idiopathic pulmonary hypertension; $\mathrm{P}_{50}$, partial pressure of oxygen at $50 \%$ saturation; $\mathrm{P}_{\bar{v}} \mathrm{O}_{2}$, mixed venous $\mathrm{PO}_{2}$; RPE, recurrent pulmonary emboli; $\dot{V}_{\mathrm{A}} / \dot{Q}$, ventilation-perfusion; $\dot{V}_{\mathrm{E}}$, minute ventilation. macologic reduction of pulmonary artery pressure with vasoactive drugs have met with some success (3-5). These drugs alter not only pulmonary vascular resistance but also cardiac output and the distribution of ventilation and perfusion in the lungs (6-8). Because these alterations may have detrimental effects on gas exchange, further development of this therapeutic approach depends upon a clear understanding of the underlying mechanisms of the gas exchange abnormality. We have, therefore, used the technique of multiple inert gas elimination to define these mechanisms.

\section{METHODS}

Seven patients referred for evaluation of unexplained pulmonary hypertension were studied. All had undergone cardiac catheterization and were shown not to have intracardiac shunt, valvular heart disease, or an elevated pulmonary artery wedge pressure. None of the patients gave a history of intravenous drug abuse, and none had evidence of pulmonary parenchymal disease on chest roentgenogram. This pattern of findings was considered to be consistent with the presence of either IPH or RPE.

Patients were classified as having IPH or RPE on the basis of their clinical history, ventilation-perfusion lung scan findings, and pulmonary angiograms. Three patients were felt to have RPE. In two of these patients this diagnosis was made by pulmonary angiography, whereas the third patient gave a history of recurrent thrombophlebitis and had a ventilationperfusion lung scan showing multiple segmental perfusion defects with a normal pattern of ventilation. The remaining four patients were felt to have IPH. Three of these patients had pulmonary angiograms showing no evidence of pulmonary emboli and the fourth had a normal ventilation-perfusion lung scaan and a compatible clinical history.

All patients were studied in the respiratory intensive care unit of The University of Michigan. A transvenous balloon tipped catheter was placed in the pulmonary artery and a polyethylene catheter was inserted into the radial or brachial artery. Patients were studied in the semirecumbent position, breathing room air. A mixture of six inert gases including sulphur hexafluoride, ethane, cyclopropane, halothane, ether, and acetone was equilibrated with 0.45 normal saline and infused intravenously for $45 \mathrm{~min}$. During the last $5 \mathrm{~min}$ of infusion, samples of expired gas, arterial blood, and mixed venous blood were collected for measurement of the partial pressures of oxygen and carbon dioxide and concentrations of the inert 
gases. Pulmonary artery systolic, diastolic, mean, and wedge pressures as well as heart rate and minute ventilation were measured during the final minute of the infusion.

Vascular pressures were measured using Statham strain gauges (Statham Instruments, Inc., Oxnard, Calif.). The partial pressures of oxygen and carbon dioxide in the arterial blood, mixed venous blood, and expired gas were measured using the Instrumentation Laboratory 313 blood gas analyzer (Instrumentation Laboratory, Inc., Lexington, Mass.) and oxygen saturation was measured with an Instrumentation Laboratory model 182 co-oximeter. The partial pressure of oxygen at $50 \%$ saturation $\left(\mathrm{P}_{50}\right)$ was calculated for each patient by tonometering a blood sample with gases that contained 3-5\% oxygen. Minute ventilation $\left(\dot{V}_{E}\right)$ was measured with a North American Draeger minute volumeter (Telford, Pa.), which was calibrated with a syringe and corrected to body temperature, pressure, and saturation. The concentrations of inert gases in blood and expired gas were measured using Varian Associates (Palo Alto, Calif.) and Beckman Instruments (Fullerton, Calif.) gas chromatographs as described $(9,10)$. The distribution of ventilation-perfusion ratios was calculated from the arterial, mixed venous, and expired gas concentrations of the six inert gases. The details of this technique and the method of calculation using a least squares, best fit analysis with enforced smoothing to minimize the effect of random experimental error has been described $(11,12)$. We have defined shunt as representing lung units with ventilationperfusion $\left(\dot{\mathrm{V}}_{\mathrm{A}} / \dot{\mathrm{Q}}\right)$ ratios $<0.005$ and dead space as units with $\dot{\mathrm{V}}_{\mathrm{A}} / \mathrm{Q}$ ratios $>100$. Cardiac output was derived from the $\dot{\mathrm{V}}_{\mathrm{E}}$ and the excretion and retention of the inert gases using the Fick principle. The $\dot{\mathrm{V}}_{\mathrm{A}} / \dot{\mathrm{Q}}$ distributions were combined with the mixed venous blood gases, cardiac output, $\dot{V}_{E}$, and $P_{50}$ in a lung model described by West and Wagner (13) to predict the arterial partial pressure of oxygen $\left(\mathrm{PaO}_{2}\right)$ assuming complete alveolar-end capillary equilibrium in each lung unit.

Six of the seven patients underwent pulmonary function tests before hospital discharge. Spirometry was performed using a rolling seal spirometer. Functional residual capacity was measured using a constant volume body plethysmograph, and the diffusing capacity for carbon monoxide was measured using a modification of the single breath method (14). Normal values for forced vital capacity and total lung capacity are from Goldman and Becklake (15), whereas the normal values for the diffusing capacity for carbon monoxide are from McGrath and Thomson (16). The $\mathrm{A}-\mathrm{aDO}_{2}$ was calculated from the arterial blood gases and respiratory exchange ratio.

\section{RESULTS}

The age, sex, and selected pulmonary function studies from our patients are presented in Table I. There were five women and two men with a mean age of $36 \mathrm{yr}$ (range, 19-56 yr). All of the patients complained of dyspnea on exertion, and four of seven had experienced chest pain and/or syncope. None of our patients were smokers. Among the patients in whom routine pulmonary function studies were done, no air flow obstruction was found and the diffusing capacity for carbon monoxide was uniformly reduced. Two patients (E.S. and L.L.) had a mild reduction in total lung capacity.

The $\dot{V}_{A} / \dot{Q}$ distributions derived from the inert gas data for the seven patients are shown in Fig. $1 .^{2}$ In all cases, the majority of pulmonary blood flow was distributed to a mode centered at or above a $\dot{V}_{A} / Q$ ratio of one. Flow to this mode averaged $90 \%$ of the cardiac output with a range of $81-98 \%$. The shape and position of this mode along the $\dot{V}_{A} / \dot{Q}$ axis did not differ significantly from that described as the distribution pattern for normal subjects of the same age (17). In all but one subject there was an additional mode of blood flow distributed to units with $\dot{\mathrm{V}}_{\mathrm{A}} / \dot{\mathrm{Q}}$ ratios of $<0.1$ and/or shunt. In the group as a whole this represented $<10 \%$ of the cardiac output although L.L. had $19 \%$ of her cardiac output going to both shunt and low $\dot{V}_{A} / \dot{Q}$ and P.D. had $17 \%$ of his cardiac output exclusively distributed to very low $\dot{\mathrm{V}}_{\mathrm{A}} / \mathrm{Q}$ units.

\footnotetext{
${ }^{2}$ The retention and excretion data are available from the authors upon request.
}

TABLE I

Pulmonary Function Data in Patients with Obliterative Pulmonary Vascular Disease

\begin{tabular}{lcccccc}
\hline \multicolumn{1}{c}{ Patient } & Sex & Age & FVC & FEV1.0\% & TLC & $\mathrm{D}_{\mathrm{L}} \mathrm{CO}$ \\
\hline $\begin{array}{l}\text { Idiopathic pulmonary } \\
\text { hypertension }\end{array}$ & & yr & \% predicted & & \% predicted & \% predicted \\
E.S. & F & 28 & 70 & 78 & 81 & 48 \\
C.J. & $\mathrm{M}$ & 27 & - & - & - & - \\
J.S. & $\mathrm{F}$ & 19 & 78 & 90 & 89 & 57 \\
L.L. & $\mathrm{F}$ & 56 & 59 & 85 & 79 & 31 \\
Recurrent pulmonary & & & & & & \\
$\quad$ emboli & & & & & & \\
A.M. & $\mathrm{F}$ & 35 & 105 & 70 & 115 & 69 \\
V.J. & $\mathrm{F}$ & 57 & 72 & 77 & 98 & 39 \\
P.D. & $\mathrm{M}$ & 32 & 80 & 80 & 93 & 55 \\
\hline
\end{tabular}

Abbreviations used in this table: FVC, forced vital capacity; FEV1.0\%, forced expiratory volume in $1 \mathrm{~s} / \mathrm{FVC}$; TLC, total lung capacity; $\mathrm{D}_{\mathrm{L}} \mathrm{CO}$, diffusing capacity for carbon monoxide. 


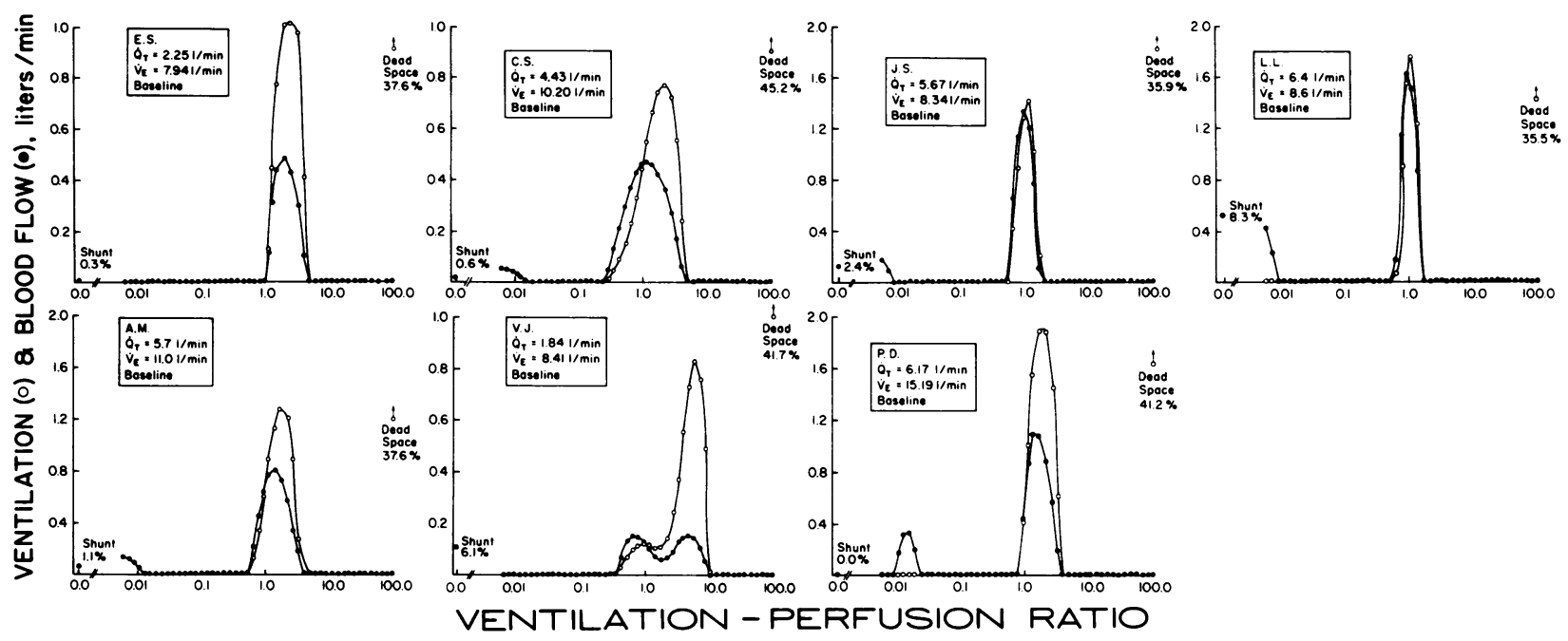

FIGURE 1 The distribution of ventilation and blood flow in seven patients with chronic obliterative pulmonary vascular disease and pulmonary hypertension. The degree of $\dot{V}_{A} / \dot{Q}$ inequality is mild with a mean of $<10 \%$ of cardiac output perfusing units with low $\dot{V}_{A} / Q$ ratios or shunt.

Hemodynamic and gas exchange indices from our patients are summarized in Table II. Hypoxemia was found in four of seven patients, but all seven showed a widened $\mathrm{A}-\mathrm{aDO}_{2}(49.6 \pm 15)$. The $\dot{\mathrm{V}}_{\mathrm{E}}$ was increased in all patients and all were hypocapnic. The cardiac index was low in four of seven $(<2.9)$. The mixed venous $\mathrm{PO}_{2}\left(\mathrm{P}_{\bar{v}} \mathrm{O}_{2}\right)$ was abnormally low $(<35$ torr) in all but two patients. The dead space as estimated by the excretion of the most soluble inert gases averaged $39 \pm 3 \%$ of $\dot{V}_{\mathrm{E}}$ or $1.2 \pm 3 \mathrm{~cm}^{3} / \mathrm{lb}$ of body weight. This is similar to that described in normal subjects (17).

Each patient's measured $\mathrm{PaO}_{2}$ was compared to his
$\mathrm{PaO}_{2}$ predicted from the derived $\dot{\mathrm{V}}_{\mathrm{A}} / \dot{\mathrm{Q}}$ distributions and the measured cardiac output, $\dot{\mathrm{V}}_{\mathrm{E}}, \mathrm{P}_{50}$ and $\mathrm{P} \overline{\mathrm{v}} \mathrm{O}_{2}$, and $\mathrm{PCO}_{2}$. The computer program used assumes complete alveolar-end capillary equilibration and solves the ventilation-perfusion equation for oxygen, carbon dioxide, and nitrogen (13). The ability to predict the $\mathrm{PaO}_{2}$ in every case was excellent over a wide range of $\mathrm{PO}_{2}$ values (Fig. 2).

\section{DISCUSSION}

Early studies of patients with pulmonary vascular occlusion suggested that their hypoxemia occurred as a

TABLE II

Hemodynamic and Gas Exchange Data in Patients with Obliterative Vascular Disease

\begin{tabular}{|c|c|c|c|c|c|c|c|c|c|c|c|c|c|}
\hline & \multirow[b]{2}{*}{$\overline{\mathrm{PAP}}$} & \multirow[b]{2}{*}{$\mathrm{Hgb}$} & \multirow[b]{2}{*}{$\dot{\mathrm{V}}_{\mathrm{E}}$} & \multirow[b]{2}{*}{$\dot{Q}_{t}$} & \multirow[b]{2}{*}{$\mathrm{CI}$} & \multirow[b]{2}{*}{$\mathrm{PaO}_{2}$} & \multirow[b]{2}{*}{$\mathrm{PaCO}_{2}$} & \multirow[b]{2}{*}{$\mathrm{PùO}_{2}$} & \multirow[b]{2}{*}{$\mathrm{A}-\mathrm{aDO}_{2}$} & \multirow[b]{2}{*}{ Shunt } & \multicolumn{2}{|c|}{ Dead space } & \multirow{2}{*}{$\begin{array}{c}\dot{Q}_{1} \text { to } \dot{V}_{A}(\dot{Q}) \\
0.1\end{array}$} \\
\hline & & & & & & & & & & & $\dot{\mathrm{V}}_{\mathrm{E}}$ & Breath & \\
\hline $\begin{array}{l}\text { Idiopathic } \\
\text { pulmonary } \\
\text { hypertension }\end{array}$ & $m m \mathrm{Hg}$ & $g \%$ & $\begin{array}{l}\text { liters/ } \\
\text { min }\end{array}$ & $\begin{array}{c}\text { liters } / \\
\min -M^{2}\end{array}$ & liters/ & \multicolumn{4}{|c|}{ torr } & $\%$ & $\%$ & $m l$ & $\%$ \\
\hline E.S. & 50 & 14.9 & 7.9 & 2.3 & 1.3 & 90 & 22 & 30 & 28 & 0.3 & 38 & 112 & 0.3 \\
\hline C.S. & 80 & 14.6 & 10.9 & 4.4 & 2.4 & 69 & 34 & 34 & 53 & 0.6 & 45 & 215 & 5.8 \\
\hline J.S. & 70 & 14.7 & 8.3 & 5.7 & 3.5 & 85 & 24 & 45 & 34 & 2.4 & 36 & 180 & 7.1 \\
\hline L.L. & 48 & 10.1 & 8.6 & 6.4 & 3.7 & 46 & 33 & 26 & 61 & 8.3 & 36 & 152 & 19.0 \\
\hline $\begin{array}{l}\text { Recurrent } \\
\text { pulmonary } \\
\text { embolism }\end{array}$ & & & & & & & & & & & & & \\
\hline A.M. & 42 & 15.6 & 11.0 & 5.1 & 2.7 & 85 & 29 & 44 & 42 & 1.1 & 38 & 268 & 8.9 \\
\hline V.J. & 65 & 12.5 & 8.4 & 1.8 & 1.2 & 58 & 28 & 24 & 71 & 6.1 & 42 & 137 & 6.1 \\
\hline P.D. & 49 & 13.3 & 15.2 & 6.7 & 2.9 & 65 & 24 & 33 & 58 & 0.0 & 41 & 220 & 17.0 \\
\hline
\end{tabular}

Abbreviations used in this table: $\overline{\mathrm{PAP}}$, mean pulmonary artery pressure; Hgb, hemoglobin; $\dot{Q}_{\mathrm{t}}$, cardiac output; CI, cardiac index. 


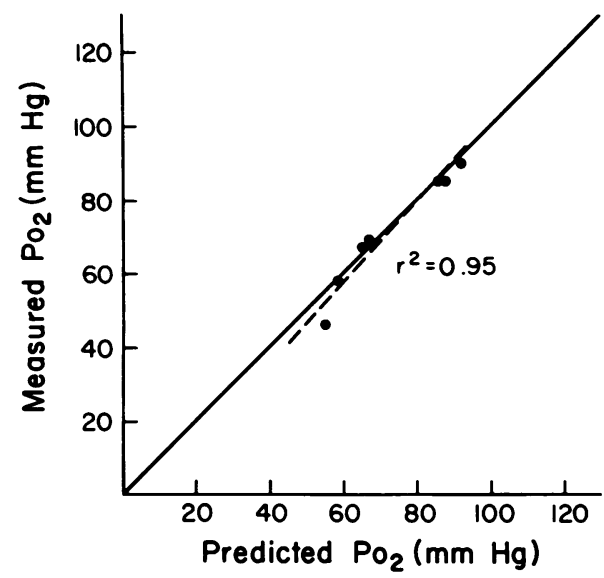

Figure 2 The measured arterial oxygen tension $\left(\mathrm{PO}_{2}\right)$ is compared with the arterial $\mathrm{Po}_{2}$ predicted from the $\dot{\mathrm{V}}_{\mathrm{A}} / \dot{\mathrm{Q}}$ distributions. The excellent correlation eliminates diffusion impairment as a contribution to the widened $\mathrm{A}-\mathrm{aDO}_{2}$.

result of decreased transit time of blood through a reduced pulmonary capillary bed with resulting failure of alveolar-end capillary equilibration (18). Recently, $\dot{\mathrm{V}}_{\mathrm{A}} / \dot{\mathrm{Q}}$ inequality and intrapulmonary shunt have been implicated as causes for the hypoxemia (19-21). A low cardiac output state with resulting reduction of mixed venous saturation has also been reported (22), but its impact on arterial hypoxemia has not been evaluated.

We have shown in seven patients with chronic obstruction to their pulmonary vascular bed that the increased $\mathrm{A}-\mathrm{aDO}_{2}$ was because of a combination of $\dot{\mathrm{V}}_{\mathrm{A}} / \dot{\mathrm{Q}}$ inequality, intrapulmonary shunt, and a low $\mathrm{P}_{\bar{v}} \mathrm{O}_{2}$. Diffusion impairment did not contribute to impaired gas exchange since the measured $\mathrm{PaO}_{2}$ was well predicted from $\dot{\mathrm{V}}_{\mathrm{A}} / \dot{\mathrm{Q}}$ distributions determined by inert gas elimination. Diffusion equilibration of these inert gases along the pulmonary capillary is complete in any lung that can sustain life (11), and any diffusion abnormality causing impairment of $\mathrm{O}_{2}$ exchange would lead to a systematic over-prediction of the $\mathrm{PaO}_{2}$ (23).

The presence of shunt and very low $\dot{V}_{A} / Q$ units in our patients may be explained by overperfusion of normal lung units. The obliteration of a large portion of the pulmonary vascular bed results in increased blood flow through the remaining pulmonary capillaries. The $\dot{\mathrm{V}}_{\mathrm{A}} / \dot{\mathrm{Q}}$ ratios of the perfused units thus fall (20). Although it is unlikely that this would lead to units with $\dot{\mathrm{V}}_{\mathrm{A}} / \dot{\mathrm{Q}}$ ratios as low as 0.01 or below, these units could result from a combination of increased blood flow and airway obstruction. This obstruction may result from the compression of bronchi running adjacent to dilated pulmonary arteries (24).

An alternative cause for both the low $\dot{V}_{A} / \dot{Q}$ units and the shunt is the development of interstitial pulmonary edema. West et al. (25) suggested that there might be a region at the base of the lung where pulmonary artery pressure is high enough to lead to interstitial edema, airway closure, and low $\dot{\mathrm{V}}_{\mathrm{A}} / \mathrm{Q}$ units. Albert and others (26) have demonstrated that a significant amount of fluid may leak from extraalveolar vessels into the pulmonary interstitium. This phenomenon may explain the pulmonary edema seen with high-altitude exposure (27) and the increase in extra-vascular lung water found during positive end-expiratory pressure ventilation (28). Ohkuda et al. (29) demonstrated interstitial edema when pulmonary artery pressure was elevated by microembolization. He attributed this increased fluid filtration to uneven increases in pulmonary vascular resistance. Our patients had very high pulmonary artery pressure which could have led to leakage of fluid into the interstitial space, either from the occluded extraalveolar vessels or from alveolar capillaries exposed to increased pressure in remaining patent vessels. This could result in airway obstruction as well as alveolar edema explaining the presence of both the low $\dot{V}_{A} / \dot{Q}$ units and shunt.

In addition to the mild $\dot{\mathrm{V}}_{\mathrm{A}} / \dot{\mathrm{Q}}$ inequality, five of seven patients had an abnormally low $\mathrm{P}_{\mathrm{v}} \mathrm{O}_{2}$. The cause of the low $\mathrm{P}^{-} \mathrm{O}_{2}$ was inadequate cardiac output alone in all but patient L.L. who was also significantly anemic with a hemoglobin concentration of $10 / \mathrm{g} 100 \mathrm{ml}$ of blood. The correlation coefficient between cardiac index and $\mathrm{P}_{\bar{v}} \mathrm{O}_{2}$ for the group excluding L.L. was $0.84(P<0.05)$. It has been well demonstrated that a low $\mathrm{P}_{\bar{v}} \mathrm{O}_{2}$ can significantly affect the $\mathrm{PaO}_{2}$ by decreasing the end-capillary $\mathrm{PO}_{2}$ of lung units with $\dot{\mathrm{V}}_{\mathrm{A}} / \mathrm{Q}$ ratios $<1$ (23). Significant hypoxemia $\left(\mathrm{PaO}_{2}<80\right.$ torr) was found in four of seven patients. In these patients it was the combination of mild $\dot{\mathrm{V}}_{\mathrm{A}} / \dot{\mathrm{Q}}$ inequality and a low $\mathrm{P}_{\bar{v}} \mathrm{O}_{2}$ that accounted for the hypoxemia. The fifth patient with a low $\mathrm{P}_{\bar{v}} \mathrm{O}_{2}$ (E.S.) had a normal $\mathrm{PO}_{2}$ because of the absence of low $\dot{\mathrm{V}}_{\mathrm{A}} / \dot{\mathrm{Q}}$ units. In the two patients whose $\mathrm{P}_{\bar{v}} \mathrm{O}_{2}$ was normal, the $\mathrm{PaO}_{2}$ was well preserved despite the presence of comparable $\dot{\mathrm{V}}_{\mathrm{A}} / \dot{\mathrm{Q}}$ inequality. The relationship of $\dot{\mathrm{V}}_{\mathrm{A}} / \dot{\mathrm{Q}}$ inequality and $\mathrm{P} \overline{\mathrm{v}} \mathrm{O}_{2}$ to the $\mathrm{PaO}_{2}$ was statistically evaluated with a multivariate analysis. Using $\mathrm{P}_{\mathrm{v}} \mathrm{O}_{2}$ as $x_{1}$ and the percentage of blood flow to units with $\dot{\mathrm{V}}_{\mathrm{A}} / \mathrm{Q}<0.1$ as $x_{2}$, the regression equation was $y=44.6+1.2 x_{1}-1.4 x_{2}$. The regression coefficient was $0.89(P<0.05)$, the partial regression coefficients of $x_{1}$ and $x_{2}$ were 0.80 and 0.77 and the standard error of $x_{1}$ and $x_{2}$ were 0.46 and 0.59 .

To quantitate the influence that the low $\mathrm{P}_{\bar{v}} \mathrm{O}_{2}$ had on the $\mathrm{PaO}_{2}$ of our patients we manipulated the lung model used to predict the arterial $\mathrm{PO}_{2}(10)$. Using the measured $\dot{\mathrm{V}}_{\mathrm{A}} / \dot{\mathrm{Q}}$ distributions, $\dot{\mathrm{V}}_{\mathrm{E}}$ and cardiac output, we constrained the $\mathrm{P}_{\bar{v}} \mathrm{O}_{2}$ to be 40 torr. In each case, increasing the $\mathrm{P}_{\bar{v}} \mathrm{O}_{2}$ in this manner lead to significant improvement in the predicted $\mathrm{PaO}_{2}$ (Table III). Although this type of manipulation does not correct for the individual factors leading to the low 
TABLE III

Effect of Increasing the $\mathrm{P}_{\bar{v}} \mathrm{O}_{2}$ on the Arterial Oxygen Tension

\begin{tabular}{lcc}
\hline & Measured $\mathrm{PaO}_{2}$ & $\begin{array}{c}\mathrm{PaOO}_{2} \text { (alculated with } \mathrm{PĩO} \mathrm{O}_{2} \\
\text { increased to } 40 \text { torr }\end{array}$ \\
\hline \multicolumn{2}{c}{ torr } \\
E.S. & 90 & 106 \\
C.J. & 69 & 78 \\
L.L. & 46 & 69 \\
P.D. & 64 & 72 \\
V.J. & 58 & 88 \\
\hline
\end{tabular}

$\mathrm{P}_{\mathrm{v}} \mathrm{O}_{2}$ it clearly demonstrates the degree to which a low $\mathrm{P}_{\bar{v}} \mathrm{O}_{2}$ accentuated the hypoxemia.

The obstruction of blood flow to a lung with normal ventilatory ability should produce significant wasted ventilation (30). The absence of an elevated dead space or a significant number of high $\dot{V}_{\mathrm{A}} / \dot{Q}$ units in our patients is, therefore, surprising. Hlastala (31), however, also found no increase in dead space in dogs in whom the pulmonary vessels were occluded with gas bubbles. He suggested two mechanisms to account for this finding. The reinspiration of common dead space gas into the units with no perfusion might cause them to appear as high $\dot{V}_{A} / Q$ units, or collateral perfusion may allow for continued perfusion of alveoli.

The lack of high $\dot{V}_{A} / Q$ units or an elevated dead space in our patients can be explained in one of two ways. First, despite the apparent decrease in the pulmonary vascular bed cross sectional area, there may not have been sufficient interruption in alveolar perfusion to interfere with normal $\dot{V}_{A} / \dot{Q}$ relationships. This might result if total occlusion of vessels did not occur or if totally occluded vessels were bypassed by collateral flow or did not supply a functionally distinct gas exchange region. Second, there may have been a compensatory shift in the ventilation distribution secondary to hypocapnic bronchoconstriction. This regulating mechanism of $\dot{V}_{A} / \dot{Q}$ matching has been well described $(32,33)$ and may markedly decrease the $\dot{V}_{\mathrm{A}} / \dot{Q}$ inequality expected in pulmonary vascular obliteration.

All of our patients were hypocapnic. Using the Siggaard-Andersen nomogram the hypocapnia was shown to be predominantly chronic and hence not related to acute ventilatory changes associated with the experimental protocol. This is consistent with the finding of other authors that hypocapnia is a common but not invariable finding in patients with both IPH and RPE $(1,34,35)$. This hypocapnia is probably because of hyperventilation induced by increased afferent activity from intrapulmonary mechanoreceptors (36).
In summary, good $\dot{V}_{A} / \dot{Q}$ relationships are maintained despite the extensive obliteration of pulmonary vascular bed found in patients with RPE and IPH. Hypoxemia in these patients results from a combination of mild $\dot{\mathrm{V}}_{\mathrm{a}} / \dot{Q}$ inequality and a low $\mathrm{P}_{\bar{v}} \mathrm{O}_{2}$. Any attempt to pharmacologically treat patients with chronic obliterative pulmonary vascular disease must be made with concern for the effects of the drugs on both cardiac output and blood flow distribution.

\section{ACKNOWLEDGMENTS}

We gratefully acknowledge the help and guidance given to us by Dr. John Weg. In addition, we wish to thank Mr. Peter DeHart for his technical contributions and Dr. Peter Abbrecht and Dr. Harold Rotman for their careful review of the manuscript.

This work was partially funded by a grant from the National Heart, Lung, and Blood Institute HL 19449.

\section{REFERENCES}

1. Gazetopoulos, N., N. Salonikides, and H. Davies. 1974. Cardiopulmonary function in patients with pulmonary hypertension. Br. Heart J. 36: 19-28.

2. Walcott, G., H. B. Burchell, and A. L. Brown. 1970. Primary pulmonary hypertension. Am. J. Med. 40: 7078.

3. Daoud, F. S., J. T. Reeves, and D. B. Kelly. 1978. Isoproterenol as a potential pulmonary vasodilator in primary pulmonary hypertension. Am. J. Cardiol. 42: $817-822$.

4. Shettigar, V. R., H. N. Hultgren, M. Spector, R. Martin, and D. H. Davies. 1976. Primary pulmonary hypertension. Favorable effect of isoproterenol. N. Engl. J. Med. 295: 1414-1415.

5. Wang, S. W. S., J. E. F. Pohl, D. J. Rowlands, and E. G. Wade. 1978. Diazoxide in treatment of primary pulmonary hypertension. Br. Heart J. 40: 572-574.

6. Dodge, H. T., J. D. Lord, and H. Sandler. 1960. Cardiovascular effects of isoproterenol in normal subjects and subjects with congestive heart failure. Am. Heart. J. 60: $94-105$.

7. Mookherjee, S., J. F. H. Keighley, R. A. Warner, M. A. Bowser, and A. I. Obeid. 1977. Hemodynamic, ventilatory and blood gas changes during infusion of sodium nitroferricyanide (Nitroprusside). Chest. 72: 273-278.

8. Wagner, P. D., D. R. Dantzker, V. E. Iacovoni, W. C. Tomlin, and J. B. West. 1978. Ventilation-perfusion inequality in asymptomatic asthma. Am. Rev. Respir. Dis. 118: $511-524$.

9. Wagner, P. D., P. F. Naumann, and R. B. Laravuso. 1974. Simultaneous measurement of eight foreign gases in the blood by gas chromatography. J. Appl. Physiol. 36: $600-605$.

10. Lynch, J. P., J. G. Mhyre, and D. R. Dantzker. 1979. Influence of cardiac output on intrapulmonary shunt. J. Appl. Physiol. 46: 315-321.

11. Wagner, P. D., H. A. Saltzman, and J. B. West. 1974. Measurement of continuous distributions of ventilationperfusion ratios:theory. J. Appl. Physiol. 36: 588-599.

12. Evans, J. W., and P. D. Wagner. 1977. Limits of $\dot{V}_{A} / \dot{Q}$ distributions from analysis of experimental inert gas elimination. J. Appl. Physiol. 42: 889-898. 
13. West, J. B., and P. D. Wagner. 1977. Pulmonary gas exchange. In Bioengineering Aspects of the Lung. J. B. West, editor. Marcel Dekker, Inc., New York. 361-458.

14. Ogilvie, C. M., R. E. Forster, M. S. Blakemore, and S. W. Morton. 1957. A standard breathing technique for the clinical measurement of the diffusing capacity for carbon monoxide. J. Clin. Invest. 36: 1-17.

15. Goldman, H. I., and M. R. Becklake. 1959. Respiratory function tests: normal values of median altitudes and the prediction of normal results. Am. Rev. Tuberc. Pulm. Dis. 79: 457. (Abstr.)

16. McGrath, M. W. and M. J. Thomson. 1959. The effect of age, body size, and lung volume change on alveolarcapillary permeability and diffusing capacity in man. J. Physiol. (Lond.). 146: 572. (Abstr.)

17. Wagner, P. D., R. B. Laravuso, R. R. Uhl, and J. B. West. 1974. Continuous distributions of ventilationperfusion ratios in normal subjects breathing air and $100 \%$ $\mathrm{O}_{2}$. J. Clin. Invest. 54: 54-68.

18. Williams, M. H. 1956. Mechanical vs reflex effects of diffuse pulmonary embolism in anesthetized dogs. Circ. Res. 4: 325-331.

19. Levy, S. E., and D. H. Simmons. 1975. Mechanism of arterial hypoxemia following pulmonary thromboembolism in dogs. J. Appl. Physiol. 39: 41-46.

20. Dantzker, D. R., P. D. Wagner, V. W. Tornabene, N. P. Alazraki, and J. B. West. 1978. Gas exchange after pulmonary thromboembolization in dogs. Circ. Res. 42: 92-103.

21. Wilson, J. E., A. K. Pierce, R. L. Johnson, E. R. IVinga, W. R. Harrell, G. C. Curry, and C. B. Mullins. 1971. Hypoxemia in pulmonary embolism, a clinical study. J. Clin. Invest. 50: 481-491.

22. Shepherd, J. T., J. E. Edwards, H. B. Burchell, H. J. C. Swan, and E. H. Wood. 1957. Clinical, physiological and pathological considerations in patients with idiopathic pulmonary hypertension. Br. Heart J. 19: 70-82.

23. West, J. B. 1977. Ventilation-perfusion relationships. Am. Rev. Respir. Dis. 116: 919-943.

24. Stranger, P., R. V. Lucas, and J. E. Edwards. 1969.
Anatomic factors causing respiratory distress in acyanotic congenital cardiac disease. Pediatrics. 43: 760. (Abstr.)

25. West, J. B., C. T. Dollery, and B. E. Heard. 1964. Increased vascular. resistance in the lower zone of the lung caused by perivascular oedema. Lancet. II: 181. (Abstr.)

26. Albert, R. K., S. Lakshminarayan, T. W. Huang, and J. Butler. 1978. Fluid leaks from extra-alveolar vessels in living dog lungs. J. Appl. Physiol. 44: 759-762.

27. Whayne, T. F. and J. W. Severinghaus. 1968. Experimental hypoxic pulmonary edema in the rat. J. Appl. Physiol. 25: 729-732.

28. Caldini, P., D. Leith, and M. Brennen. 1975. Effects of continuous positive-pressure ventilation on edema formation in dog lung. J. Appl. Physiol. 39: 672-679.

29. Ohkuda, K., K. Nakahara, and N. C. Staub. 1976. Changes in lung fluid and protein balance in sheep after microembolism. Physiologist. 19: 315.

30. Severinghaus, J. W. and M. Stupfel. 1957. Alveolar dead space as an index of distribution of blood flow in pulmonary capillaries. J. Appl. Physiol. 10: 335348.

31. Hlastala, M. P., H. T. Robertson, and B. K. Ross. 1979. Gas exchange abnormalities produced by venous gas emboli. Respir. Physiol. 36: 1-17.

32. Swenson, E. W., T. V. Finley, and S. V. Guzman. 1961. Unilateral hypoventilation in man during temporary occlusion of one pulmonary artery. J. Clin. Invest. 40: $828-835$.

33. Levy, S. E., and D. H. Simmons. 1974. Redistribution of alveolar ventilation following pulmonary thromboembolism in the dog. J. Appl. Physiol. 36: 60-68.

34. Nadel, J. E., W. M. Gold, and J. H. Burgess. 1968. Early diagnosis of chronic pulmonary vascular obstruction. Am. J. Med. 44: 16-24.

35. Kafer, E. R. 1969. Respiratory function in pulmonary thromboembolic disease. Am. J. Med. 47: 904-915.

36. Guz, A., M. I. M. Noble, J. H. Eisele, and D. Trenchard. 1970. Experimental results of vagal block in cardiopulmonary disease. In Breathing: Hering-Breuer Centenary Symposium. J. \& A. Churchill Ltd., London, 315-329. 